\title{
PATRIMÔNIO, TURISMO CULTURAL E EDUCAÇÃO PATRIMONIAL
}

\author{
Alessandro de Melo* \\ Poliana Fabiula Cardozo**
}

\begin{abstract}
RESUMO: Trata-se de um artigo de revisão de literatura sobre a relação entre educação patrimonial, concepçóes de patrimônio e o turismo cultural. Defende-se que existe a necessidade de desenvolver açóes interdisciplinares em políticas de turismo e educação patrimonial, para o melhor aproveitamento do patrimônio, ampliando sua atratividade para as cidades, bem como enriquecendo a experiência dos turistas, partindo da concepção de patrimônio como a herança produzida pelos homens em sociedade, e, logo, parte integrante da formação humana.
\end{abstract}

Palavras-chave: Educação patrimonial. Turismo cultural. Patrimônio cultural. Educação. Revisão de literatura.

\section{HERITAGE, CULTURAL TOURISM AND HERITAGE EDUCATION}

ABSTRACT: This is a review of literature on the relationship between heritage education, conceptions of heritage and cultural tourism. It is advocated that there is a need to develop interdisciplinary actions on tourism and heritage education policies, for a better use of assets, increasing their attractiveness for the cities, as well as enriching the experience of tourists, starting from the conception of heritage as that which is produced by men in society, and therefore, an integral part of human development.

Keywords: Heritage education. Cultural Tourism. Cultural heritage and education. Literature review.

\footnotetext{
* Universidade Estadual do Centro-Oeste, Programa de Pós-graduação em Educação. Guarapuava, PR., Brasil. E-mail de contato: alessandrodemelo2006@hotmail.com.

** Universidade Estadual do Centro-Oeste, Programa de Pós-graduação Mestrado em Educação. Irati, PR., Brasil. E-mail de contato: polianacardozo@yahoo.com.br.
} 


\section{LE PATRIMOINE, LE TOURISME CULTUREL ET L'ÉDUCATION AU PATRIMOINE}

RÉSUMÉ: Il s'agit d'un article de revue sur la relation entre l'éducation au patrimoine, les conceptions du patrimoine et le tourisme culturel. On soutient qu'il est nécessaire de développer des actions interdisciplinaires sur les politiques de tourisme et de l'éducation pour une meilleure utilisation des actifs, en augmentant son intérêt pour les villes, en plus d'enrichir l'expérience des touristes, à partir de la conception du patrimoine comme l'héritage produit par les hommes dans la société et donc partie intégrante de la formation humaine.

Mots-clés: Éducation au patrimoine. Tourisme culturel. Patrimoine culturel et l'éducation. Revue de la littérature.

\section{Introdução}

A

discussão sobre o patrimônio cultural vem sendo levada a efeito por diversos intelectuais, destacando-se Choay (2001), Barretto (2003), Banducci Jr. e Barretto (2001), Urry (1996), Castrogiovanni e Gastal (1999), Santana Talavera (1997; 2003). Este artigo pretende realizar uma discussão sobre as possibilidades dos usos do patrimônio como mediação para a educação patrimonial e da atratividade turística.

O patrimônio é compreendido como a objetivação da produção histórico-social da humanidade, e, portanto, necessita ser socializada, o que é o objetivo da educação patrimonial. A socialização e a apropriação do patrimônio integram a formação genérica do ser humano (DUARTE, 1993), e o alijamento dos homens em relação ao patrimônio é indício de um processo desumanizador. Um pensamento similar ao da Unesco, que, em 1972, na Convenção para a Proteção do Patrimônio Mundial, Cultural e Natural, afirma que a destruição de um patrimônio "[...] constitui um empobrecimento efectivo do património de todos os povos do mundo."

$\mathrm{O}$ anteriormente exposto assenta-se sobre a concepção de que a humanidade não é dada naturalmente a cada indivíduo, mas é construída social e historicamente pelas relaçóes que estes indivíduos possuem com a produção humana. (SAVIANI, 2000) Logo, o enriquecimento dos indivíduos passa necessariamente pela apropriação, por cada indivíduo, dos resultados desta produção, o que é o objetivo do trabalho educativo.

O turismo cultural pautado pela ação de visitação e conhecimento do patrimônio cultural possui um sentido educativo, pois é uma mediadora no 
processo de socialização e apropriação dos bens humanos materializados nos patrimônios, que são os atrativos das cidades turísticas. A educação patrimonial como mediadora da atividade turística, ao promover o contato, a socialização e a apropriação do patrimônio pelos turistas, contribui nesta tarefa da produção do ser humano genérico, ou seja, constitui uma forma de realização do trabalho educativo. Para isso é necessário planejar a atividade turística com o patrimônio na intencionalidade de produzir esta socialização e apropriação, assim como é necessário o planejamento de um projeto de educação patrimonial. Este artigo pretende contribuir com uma base epistemológica para o desenvolvimento desta atividade.

$\mathrm{O}$ artigo será dividido em três partes. $\mathrm{Na}$ primeira será tratada a concepção geral de patrimônio, para iniciar a discussão no plano escolhido, e que tem repercussóes em todo o plano do artigo, já que é a partir do que se considera patrimônio que é desenvolvida a ideia de uma educação para o patrimônio. $\mathrm{Na}$ segunda parte são analisadas as ideias de material e imaterial, relativas ao patrimônio. $\mathrm{Na}$ terceira parte discute-se a necessidade da preservação e conservação do patrimônio como objetivo da educação patrimonial e da atividade turística.

\section{A concepção de patrimônio em geral}

O senso comum conceitua o patrimônio como sendo tudo o que se tem em posse, o que se acumula na vida, material e imaterialmente, fruto do trabalho. Assim, o ser humano, ao longo da vida, constrói e mobilia sua casa, compra um automóvel e, enfim, produz as suas condições individuais e familiares de vida. Este conjunto de bens materiais é chamado de patrimônio, o qual será objeto de herança e partilha em caso de morte do mantenedor e no caso de este ter mais que um herdeiro. Ao longo da vida, de geração em geração, os pais transmitem para os filhos seus valores éticos, como a honestidade, o trabalho, a perseverança, a necessidade da fé para guiar a vida, entre outros. A este conjunto de valores dá-se o nome de patrimônio moral. Poderíamos multiplicar os exemplos destas concepçóes de patrimônio.

Embora a concepção que procuramos desenvolver não seja esta, não é de pouca importância que se os tome como ponto de partida para a reflexáo que ora pretende-se levantar, ou seja, a definição de patrimônio segundo o materialismo histórico. $\mathrm{O}$ que há de comum no exposto acima sobre os tipos de patrimônio, material e moral, é que ambos se articulam como resultados da produção humana, do trabalho, e que, nesta condição, são transmitidos pelas gerações antigas para as novas geraçóes. 
O patrimônio, em especial o patrimônio cultural objeto da educação patrimonial, é definido como todo patrimônio que resulta da ação humana, ou seja, das açóes das pessoas em sociedade. A Organização das Naçóes Unidas para a Educação, a Ciência e a Cultura (Unesco) divide em três os tipos de patrimônio cultural: Monumentos, Edificações e Sítios.

Claro está que a constituição do patrimônio não se dá fora do contexto sócio-histórico em que este se encontra, e não é independente das conjunturas políticas das sociedades consideradas. O patrimônio de uma sociedade é uma escolha desta sociedade sobre aquilo que lhe é mais representativo, e esta escolha depende das relaçóes sociais constituídas no interior da sociedade, o que significa relaçôes de força e de hegemonia, compreendida esta como a capacidade que um determinado grupo tem de mobilizar a maior parte da sociedade, ou toda ela, em torno de seu projeto, pautado, sobretudo, no convencimento, não na força física. (GRAMSCI, 2001) Por esta razão é que, por muito tempo, considerou-se patrimônio no Brasil apenas os conjuntos arquitetônicos, as obras relacionadas ao que a história tradicional trata de grandes acontecimentos, grandes heróis, e tudo o mais era descartado desta lista. $\mathrm{Na}$ verdade, os conjuntos arquitetônicos e outras edificações consideradas patrimônio eram resultados das ações das classes dominantes nos diferentes períodos da história brasileira, e, como classes dominantes, tinham o poder hegemônico de tornar suas ações e feitos, como ações e feitos que deveriam ser considerados como relevantes para toda a sociedade.

A definição de Patrimônio, portanto, vai além das duas classificações como patrimônio material e imaterial, segundo o faz a Unesco, em termos mundiais, e o Instituto do Patrimônio Histórico e Artístico Nacional (Iphan), no Brasil. Para entender a questão do patrimônio como uma questão sócio-histórica é preciso mergulhar nas relações sociais fundamentais existentes na sociedade brasileira, e na dominação de classe que pauta fundamentalmente esta sociedade.

O caso de Ouro Preto, que foi um dos primeiros patrimônios brasileiros reconhecidos pela Unesco, em 1980, ilustra bem o caso desta dominação. Como todos sabemos, a cidade de Ouro Preto foi fundada pela necessidade dos portugueses, aqui residentes, de explorar o ouro descoberto nas Minas Gerais, e cuja exploração foi realizada com o trabalho escravo dos negros de origem africana. Portanto, temos um grupo que explorava o trabalho e o outro que verdadeiramente produzia, pois estava forçado a isso. Logo, o que vemos como patrimônio cultural, ou seja, a bela cidade de Ouro Preto, foi resultado de trabalho escravo, embora estes homens e mulheres que a construíram não aparecem na história oficial, não se configuram como "personagens" da história brasileira, sujeitados que estão sob a pecha da escravidão. Não existem Tiradentes, mas simplesmente escravos, anônimos e desconsiderados, cujos herdeiros continuam vivendo nas periferias desta e de outras cidades mineiras e brasileiras. 
Trabalhar com o patrimônio na perspectiva aqui delineada significa levar em conta as relaçóes reais levadas a efeito por homens reais em situaçóes históricas concretas. Sem a pretensão de responder à questão, mesmo assim é relevante coloca-la à colação: como desenvolver, neste caso concreto de Ouro Preto, um projeto turístico que evidencie as relações sociais que levaram à produção concreta do patrimônio que é objeto da atividade turística? Conhecer e se apropriar do patrimônio Ouro Preto não pode ser um ato ahistórico, acrítico, mas, ao contrário, deve ser um ato que perpasse pela apropriação das dinâmicas sociais, culturais e históricas de produção do patrimônio.

Trata-se da dinâmica da apropriação das objetivaçóes, ou seja, como o turista, imerso num projeto intencional de turismo cultural, pode se apropriar do patrimônio objetivado, por exemplo, em Ouro Preto. Segundo Martins (2004, p. 55), trata-se, esta dinâmica, de um processo educativo:

Consideremos, de partida, que a educação é um processo que
não pode ser eliminado do desenvolvimento humano e uma das
condiçóes pelas quais o ser humano adquire seus atributos fun-
damentais ao longo do processo histórico social [...] A dinâmica
apropriaçáo-objetivaçáo ocorre sempre em condiçóes que são
históricas, e, dessa forma, para que os indivíduos se objetivem
como seres humanos, é preciso que se insiram na História.

Educar-se, portanto, é adquirir os atributos humanos, que são, por sua vez, construçóes históricas, afinal o ser humano não se faz naturalmente, mas em coletivo, por açóes intencionais e por escolhas socialmente colocadas em jogo. Todo o ser do homem é social, inclusive a forma como usa o corpo biológico, como bem ilustra Laraia (2001) em sua introdução à discussão sobre cultura. $\mathrm{O}$ que faz a atividade turística, neste sentido? Ela pode ser também, e inclusive intencionalmente, uma ação educativa, no sentido de favorecer, pela dinâmica da apropriação do patrimônio pelos turistas, a sua humanização.

A esta altura não podemos deixar de comentar o que significa o patrimônio nesta constituiçáo do ser do homem. O patrimônio em todas as suas formas é o resultado das ações humanas legadas para as próximas geraçóes, sejam elas objetivadas em edifícios ou um conjunto urbano de caráter histórico, seja na forma imaterial, objetivada nas tradiçóes, formas de fazer, de construir artefatos ou instrumentos musicais, de produzir alimentos, de pinturas corporais e outras manifestaçóes. Desta forma, conhecer os diferentes tipos de patrimônio, e se apropriar da forma como cada um é e foi desenvolvido, as motivaçóes e escolhas envolvidas no ato de transformação das produçóes humanas em patrimônio, significa promover os indivíduos a uma condição cultural mais elevada, no sentido da sua formação mais rica de elementos culturais. É justamente esta riqueza o objetivo da ação educativa, de caráter intencional, que permeia a atividade turística cultural. 
O ser humano distingue-se dos animais, entre outras coisas, pelo fato de que produz sua existência, e faz isso tanto no que se refere às dimensóes materiais, quanto simbólicas. É esta a premissa localizada no pensamento de Marx e Engels, na clássica obra $A$ Ideologia Alemã, ou seja, o ser humano é o que e como produz, nas condiçóes históricas e sociais que lhes é dado fazer isso:

Da maneira como os indivíduos manifestam sua vida, assim são eles. O que eles são coincide, portanto, com sua produção, tanto com $o$ que produzem como com $o$ modo como produzem. $\mathrm{O}$ que os indivíduos são, por conseguinte, depende das condiçóes materiais de sua produção. (MARX; ENGELS, 1993, p. 19)

A atividade turística, ao colocar frente a frente turistas e o legado cultural na forma de patrimônio, propicia o intercâmbio e, logo, a apropriação deste legado, que está objetivado em diferentes formas, que, direta ou indiretamente são expressóes das diferentes formas humanas de ser e existir no tempo e no espaço. Ao realizar uma ação educativa no patrimônio, o que se faz é planejar metodologias e conteúdos para fazer com que aquele que não conhece o patrimônio, o turista, se aproprie destas formas humanas de expressão. ${ }^{1}$

Uma pauta importante para esta discussão é a necessidade de democratização do patrimônio, uma vez que este é entendido como as formas humanas de expressão da vida social no tempo e no espaço. Fica claro, por exemplo, que o alijamento da população do contato e apropriação de bens culturais básicos, como a leitura e a escrita, traz consequências danosas para a sociabilidade, já que vivemos em uma sociedade estritamente pautada pela escrita. No entanto, náo damos a frequente atenção quando se trata da socialização de bens culturais não tão visíveis, mas que, frequentemente, estão presentes na vida cotidiana, no caso do patrimônio em relação à população que recebe o turismo, ou que fazem parte do patrimônio de outras culturas, e cuja apropriação, por formas estruturadas e intencionais de educação, podem ampliar o horizonte cultural dos turistas. Pode-se afirmar, também, que a dimensão educativa do turismo nem sempre é pautada como relevante pelas políticas deste setor, o que contribui, por exemplo, para o estado incipiente da chamada interpretação patrimonial em nossos destinos turísticos.

A ampliação do horizonte cultural dos sujeitos por meio da atividade turística pode significar, em termos das referências aqui utilizadas, uma aproximação entre a vida individual, cotidiana, com a vida genérica do ser humano, superando a distância que aparta, de forma até mesmo violenta, cada ser humano de sua vinculação genética com a humanidade. Neste sentido, a atividade turística pode realmente ser um veículo de aproximaçáo dos povos e, logo, promotora de uma cultura da paz e do respeito à diversidade cultural. ${ }^{2}$ 
Um fato deve ser levado em conta neste sentido: a situação contemporânea vincula, por meios técnicos e científicos que facilitam a comunicação entre o mundo todo, uma proximidade e uma conexão reais, que se verifica concretamente na economia e em outras áreas da vida humana. A globalização, que é uma condição também da cidadania, exige cada vez mais cidadania global, e a atividade turística é uma mediadora desta construção, já que aproxima, metódica e intencionalmente, diferentes culturas, compondo em cada indivíduo, com os conhecimentos apropriados, uma formação que vá além do que teria contato cotidianamente, e que, pelas características do cotidiano, reduzem a vivência a círculos físicos e culturais restritos.

Para tornar a discussão mais específica, na próxima parte do artigo realizaremos uma breve discussão sobre as formas material e imaterial do patrimônio, conforme a segmentação atualmente utilizada no Brasil e pela Unesco.

\section{0 patrimônio cultural: material e imaterial}

Nesta parte utilizamos especialmente a análise realizada por Barretto (2003) sobre a história do patrimônio no Brasil. De forma ampla, é necessário considerar que a escolha sobre o que é ou não patrimônio se relaciona com a própria forma de ser da sociedade considerada, e no caso, a brasileira. Esta, como analisou em profundidade Florestan Fernandes (1974), possui como sua característica uma histórica exploração das classes dominantes que se alternaram no poder ao longo dos séculos, em relação às classes subalternas. Além disso o Brasil, nesta ótica, se constituiu como um país pautado pela exclusão das maiorias em detrimento do privilegiamento das minorias, que, no entanto, sempre detiveram o poder, em uma relação promíscua entre o público e o privado, relação esta que Raymundo Faoro (2001) denominou de patrimonialismo.

Numa formação social deste tipo, não é de surpreender que as políticas de patrimônio, instaladas na década de 30 do século XX, pelas mãos de Getúlio Vargas [N.E.: Getúlio Dornelles Vargas, 14o e 17º. Presidente do Brasil, nos períodos, respectivamente, 1930-1945 e 1951-1954], só poderiam mesmo identificar como tal aqueles conjuntos monumentais, cidades, edifícios etc., que se referissem à chamada história dos vencedores (ex parte principe), e que, pelo contrário, tudo o que se referisse às conquistas populares, suas tradiçóes, construçóes, formas de viver e fazer etc., seriam simplesmente desconsideradas.

Aqui podemos fazer um paralelo com o que ocorre com a produção do currículo escolar. Este é, como o patrimônio, uma escolha social, mas neste caso o que se escolhe é a porção dos conhecimentos e da realidade ou das possibilidades humanas para serem transmitidas para as novas geraçóes. O que não está no 
currículo não existe, ou não é pensado ou ensinado, e, logo, é desconsiderado. $\mathrm{O}$ mesmo ocorre com o patrimônio. Todas as manifestaçóes populares foram simplesmente desconsideradas na produçáo social do patrimônio brasileiro, o que é característico de um país que sempre ignorou e explorou o povo, ou que este sempre foi considerado na medida em que apenas deveria servir as classes dominantes. A leitura seminal de Florestan Fernandes e Raymundo Faoro, com suas distintas posiçóes, é fundamental para a compreensão deste processo.

É justamente esta a análise produzida por Barretto (2003), voltada para as discussóes sobre patrimônio. A autora afirma que o reconhecimento do que é culturalmente relevante para ser denominado de patrimônio cultural varia conforme o conceito que se tenha de cultura e de relevância cultural, que são, por sua vez, conceitos que respeitam a dinâmica histórica e as relaçóes sociais. A mesma autora indica dois momentos da periodização do patrimônio cultural no Brasil, cuja cisão ocorre com a ascensão do movimento que ficou conhecido como a nouvelle histoire, ou a Nova História, no século XX, a partir da França. ${ }^{3}$

No período anterior ao advento e dominância da nouvelle histoire, a concepção de patrimônio cultural era a de que este se compunha dos elementos marcantes de uma história dos grandes acontecimentos, dos grandes personagens históricos, dos heróis nacionais, os grandes monumentos que faziam alusão a estes heróis etc. $\mathrm{O}$ que valia era o que a chamada História Oficial contava. Neste sentido diz a autora:

Até a primeira metade deste século, praticamente, patrimônio cultural foi sinônimo de obras monumentais, obras de arte consagradas, propriedades de grande luxo, associadas às classes dominantes, pertencentes à sociedade política ou civil.

Os prédios merecedores de cuidados especiais e exibidos eram antigos palácios, residência de nobres ou locais onde aconteceram fatos relevantes para a História política de determinado local. (BARRETTO, 2003, p.9-10)

A característica do patrimônio até este momento é o ufanismo da História Oficial, história contada a partir do ponto de vista dos vencedores, ou melhor, das classes dominantes. O ufanismo também se caracterizava como nacionalista, no sentido de identificar a História do Brasil com os heróis que, com seus atos de bravura, teriam construído a nossa identidade nacional, ou, como o caso dos bandeirantes, teriam sido os responsáveis pelas descobertas de nossas riquezas. ${ }^{4}$

Em termos educacionais, o trabalho com o patrimônio nesta perspectiva tinha como objetivo a transmissão para as novas geraçóes de uma crença nos grandes heróis, seus feitos marcantes e datas históricas relevantes, que ignoravam de todo a luta popular, os feitos do povo e, por fim, o fato de que a construção 
do país se deveu ao trabalho árduo, escravo inclusive, de milhões de pessoas que simplesmente não conhecemos, que não estudamos, que não possuem seu dia comemorativo etc.

Este processo indica, essencialmente, um processo de hegemonia, no qual as ideias dominantes numa determinada sociedade são as ideias da classe dominante, como já afirmaram Marx e Engels em A Ideologia Alemã. (MARX; ENGELS, 1993) Tal classe, por meio dos seus aparatos de Estado e outros determinados pelo seu poder econômico, consegue ter a hegemonia da transmissão para a sociedade de suas versóes da História. A escola se transformou, por muito tempo, em um locus acrítico de transmissão destes tipos de conteúdo, e, com isso, uma instituição reprodutora da ideologia dominante.

Esta visão da História, do ponto de vista dos vencedores, passa a ser questionada a partir da ascensão da nouvelle histoire na França, nas décadas de 1920 e 1930. Segundo esta perspectiva histórica, o modo de contar e transmitir a História não poderia se valer apenas dos fatos como eram oficialmente produzidos e transmitidos. Era preciso alargar o campo das possibilidades históricas. O que mais caracteriza esta perspectiva histórica é que ela adota, como meios para contar a História, materiais, falas, documentos, personagens etc., que sempre foram discriminados pela historiografia oficial. Passa-se, por exemplo, a valorizar a história do cotidiano, das classes subalternas, das organizaçóes clandestinas, dos estudos de caso, o estudo da História dos valores, crenças entre outros temas.

Para a concepção de patrimônio, esta mudança é significativa, pois implica a ascensão de uma concepção menos elitista de História. Alargou-se a compreensão sobre o significado de patrimônio cultural, que passou a abarcar "[...] utensílios, hábitos, usos e costumes, crenças e formas de vida cotidiana de todos os segmentos que compuseram e compóem a sociedade." (BARRETTO, 2003, p. 11) $)^{5}$

Esta interpretação do significado do que é ou não patrimônio, conferida desde a ascensão da Escola dos Annales, está materializada no chamado patrimônio imaterial, estabelecido pela Unesco na Convenção para a Salvaguarda do Patrimônio Cultural Imaterial ocorrida em 17 de outubro de 2003, em Paris. (UNESCO, 2003) Neste documento salienta-se uma preocupação com o papel do patrimônio imaterial sobre as relaçóes humanas, ou seja, o patrimônio cultural imaterial é uma fonte, segundo a Unesco, do reconhecimento e respeito à "[...] diversidade cultural e garantia de desenvolvimento sustentável.” (UNESCO, 2003) Este organismo internacional preocupa-se com o desenvolvimento de uma cultura da paz entre os povos, pelo respeito às diferenças culturais e se coloca contra o movimento de intolerância que surge com a globalização e a crise econômica.

Outra ênfase do texto está no reconhecimento de que o patrimônio imaterial é produzido e mantido pelas comunidades, como as comunidades indígenas, 
sendo um fator importante para enriquecer a "diversidade cultural e a criatividade humana” (UNESCO, 2003, p. 3) e, ainda, aponta para a necessária conscientização das novas geraçóes a respeito deste tipo de patrimônio da humanidade.

rial:

Tendo estes princípios, o documento define assim o patrimônio imate-

Entende-se por patrimônio cultural imaterial as práticas, representaçóes, expressôes, conhecimentos e técnicas - junto com os instrumentos, objetos, artefatos e lugares culturais que lhes são associados - que as comunidades, os grupos e, em alguns casos, os indivíduos reconhecem como parte integrante de seu patrimônio cultural. Este patrimônio cultural imaterial, que se transmite de geração em geração, é constantemente recriado pelas comunidades e grupos em função de seu ambiente, de sua interação com a natureza e de sua História, gerando um sentimento de identidade e continuidade e contribuindo assim para promover o respeito à diversidade cultural e à criatividade humana. (UNESCO, 2003, p. 4)

No trecho destacado está presente uma concepção muito diferente daquela da história oficial. Ascende, por fim, uma história ex parte populi, ou seja, uma história contada a partir do povo, daqueles considerados historicamente como vencidos, ou, na concepção aqui defendida, as classes dominadas e exploradas.

Em lugar dos heróis nacionais e seus feitos, das estátuas de bustos famosos, de casarões e palacetes, o que se privilegia como patrimônio imaterial são as representaçóes, saberes, expressões, celebrações, crenças e lugares culturais, que são parte importante da construçáo das identidades de grupos que sempre foram desconsiderados. Está expressa no texto a valorização de tudo aquilo que advém das comunidades tradicionais e do povo em geral, cuja transmissão se dá ainda pela cultura oral e geracional, ou pelo aprendizado da experiência etc.

No Brasil a Resolução no 1 , de 3 de agosto de 2006, do Iphan, dá ao conceito de patrimônio cultural imaterial algo que lhe é inerente, ou seja, seu caráter "dinâmico e processual" como fator de identidade de grupos sociais e de indivíduos.

No caso brasileiro, é interessante citar o Ofício das Baianas do Acarajé, que foi tombado em agosto de 2005 como patrimônio imaterial brasileiro ${ }^{6}$. Neste caso o que foi valorizado não é o alimento em si, mas o trabalho das mulheres neste ofício, que é uma síntese da história dos negros e da escravidão no Brasil, algo que era impensável antes dos anos 2000 no Brasil.

Não se pretende fazer a apologia do patrimônio imaterial como uma saída para as misérias das classes subalternas, pois é imperioso não se perder de 
vista que estas misérias são consequências estruturais da sociedade capitalista, em sua especificidade brasileira. (FERNANDES, 1974) Os movimentos ocorridos no campo do reconhecimento do patrimônio imaterial não estão fora desta dinâmica, ou seja, este reconhecimento não leva de fato à formulação de uma nova conjuntura de forças na sociedade, mas ela se dá no âmbito legal e não atinge o cerne da disputa ideológica na sociedade brasileira. Apesar do reconhecimento das populaçóes e grupos sociais das classes trabalhadoras, este reconhecimento não passa de forma sem conteúdo verdadeiramente transformador, o que sem dúvida não retira o mérito destas conquistas.

Voltando para a questão do patrimônio cultural, o exposto acima sobre o patrimônio imaterial, inclusive com relação ao documento destacado, está no campo mais abrangente de uma concepção de patrimônio cultural elaborado desde 1972 pela Unesco, em sua Convenção para a Proteção do Patrimônio Mundial, Cultural e Natural. Neste importante documento, lê-se como definição de patrimônio cultural:

- os monumentos: obras arquitetônicas, esculturas ou pinturas monumentais, objetos ou estruturas arqueológicas, inscrições, grutas e conjuntos de valor universal excepcional do ponto de vista da História, da arte ou da ciência;

- os conjuntos: grupos de construçóes isoladas ou reunidas, que, por sua arquitetura, unidade ou integração à paisagem, têm valor universal excepcional do ponto de vista da História, da arte ou da ciência,

- os sítios: obras do homem ou obras conjugadas do homem e da natureza, bem como áreas, que incluem os sítios arqueológicos, de valor universal excepcional do ponto de vista histórico, estético, etnológico ou antropológico. (apud BARRETTO, 2003, p. 12)

Entre este documento produzido em 1972 e aquele de 2003, sobre o patrimônio imaterial brasileiro, há uma diferença que não está apenas nos mais de 30 anos que os separam: é a própria concepção de História, de sociedade, de homem e de humanidade que está em jogo neste processo. Transformou-se o que socialmente se considera cultura e, mais, do que se considera relevante culturalmente, e, logo, relevante para ser transmitido para as novas geraçóes.

De qualquer forma, seja material ou imaterial, o patrimônio, como foi visto, é sempre o resultado da ação humana e, logo, deve ser democratizada a apropriação destes patrimônios para toda a população, num projeto educacional mediado pelo turismo. 


\section{A preservação/conservação do patrimônio como objetivo da ação turística e educativa}

A política de patrimônio tem como objetivo a preservação e conservação do conjunto do patrimônio pertencente ao povo em questão. Sem esta ação preliminar, a ação do tempo ou outras transformações mal planejadas podem danificar irremediavelmente o patrimônio e, com isso, perder-se a possibilidade de utilizá-lo da forma como vimos discutindo até aqui. O patrimônio cultural, material ou imaterial, somente tem sentido se existir de forma que possa ser apropriado pelos visitantes.

Esta preocupação é do mundo inteiro, pois a destruição dos patrimônios culturais, seja através do vandalismo, das guerras ou mesmo pela alienação cultural, é um processo de grande perda para a humanidade, pois cada patrimônio perdido é um esforço humano que se perde, é um elemento de humanidade que se esgota.

Apesar da relevância em tornar o patrimônio disponível para todos, as formas de fazer isso póe em jogo muitos interesses, especialmente os que envolvem a propriedade particular e os interesses políticos. O processo de tombamento do patrimônio coloca, por exemplo, limitaçóes econômicas para os proprietários de certos bens, como os casarôes localizados em cidades históricas tombadas etc. Entram em choque, nestes casos, os interesses públicos e privados, aqueles voltados para o uso público do patrimônio, pela apropriação deste como elemento da cultura, e, por outro lado, os interesses privados, que perseguem apenas as possibilidades de lucro com as propriedades, ou menos que isso, se relacionam com o poder que tem os proprietários de manter os imóveis em bom estado e as formas de o Estado auxiliar neste intento, já que, propriedade privada ou não, o patrimônio é responsabilidade compartilhada com o Estado.

Em meio a esta disputa estão as políticas públicas de preservação e conservação do patrimônio. Desde o âmbito internacional a Unesco, em 1972, quando da Convenção para a preservação do patrimônio mundial, colocava esta questão. As ameaças aos patrimônios são diversas, desde as causas naturais, dadas pela exposição e pelo tempo, elementos inexoráveis dos patrimônios materiais, como as ameaças advindas das relaçôes sociais, em especial nos países politicamente instáveis, em que as mudanças poderiam levar à destruição dos patrimônios culturais. O turismo também foi considerado como elemento que poderia ser pernicioso para este objetivo de preservação e conservação do patrimônio, haja vista que através desta atividade muitas pessoas visitam os patrimônios e pode haver, com isso, problemas de várias espécies para o bem cultural.

Barretto (2003, p. 13) expóe com convicção que outros elementos entram neste debate. 
Para proteger o patrimônio dessas ameaças, são necessárias políticas de preservação. Essas políticas não são neutras, espelham a ideologia dos que fazem as leis. Determinar o que é digno de preservação é uma decisão político-ideológica, que reflete valores e opiniōes sobre quais são os símbolos que devem permanecer para retratar determinada sociedade ou determinado momento, donde os grandes questionamentos sobre quem tem ou deveria ter autoridade para decidir.

A não-neutralidade das políticas de preservação do patrimônio é um elemento sine qua non de um debate maior, ou seja, o próprio papel do Estado na sociedade capitalista. Este, desde o seu nascimento, sempre foi elemento determinante de manutenção do status quo da sociedade, ou seja, sempre esteve a serviço das classes dominantes de cada período, que, por sua vez, moldaram e limitaram a ação deste Estado para a defesa de seus interesses.

No momento atual de hegemonia do modelo de estado neoliberal (ANDERSON, 2003), cuja maior característica é a sua omissão sobre as questôes mais relevantes socialmente como educação, saúde, saneamento básico etc., parece claro que o investimento em políticas culturais em geral, e especialmente políticas de defesa do patrimônio cultural, não sejam prioridades. Mas, o que é a própria contradição neste caso, o mesmo Estado omisso quanto ao patrimônio é o responsável por articular e desenvolver as políticas de preservação do patrimônio. O tombamento é responsabilidade de um Estado que, apesar de indicar os elementos patrimoniais para o tombamento, não possui condiçóes nem vontade política de realizar a sua manutenção, o que se configura numa situação paradoxal. (BARRETTO, 2003)

Desta forma, as possibilidades de existência concreta e desenvolvimento de projetos turísticos de caráter educativo nos patrimônios passam, também, pela ação do Estado e a pressão da sociedade civil para a inversão nestas políticas. A saída que tem sido a privilegiada é a das parcerias entre o setor público ou privado ou o modelo de concessóes existentes, por exemplo, nos parques nacionais, o que é uma amostra da ineficiência do Estado em cuidar por si mesmo do patrimônio cultural. Seria uma discussão interessante a problematização de se entregar para mãos privadas bens de caráter público, e as consequências sociais destas decisóes políticas.

\section{Considerações finais}

As discussões aqui levantadas sobre a relação entre patrimônio, turismo e educação podem ser ferramentas de açóes educativas que visam à valorização do 
patrimônio cultural material ou imaterial como mediadores formativos, pensando a constituição do indivíduo e da individualidade como processo de vínculo entre a herança socialmente construída, o patrimônio, e processos intencionais para sua disseminação e apropriação, a educação patrimonial. Desta forma, a mediação educativa do uso público do patrimônio torna-se uma poderosa ferramenta para o desenvolvimento de políticas de turismo nas cidades, ampliando a atratividade e gerando experiências turísticas culturais enriquecedoras.

Esta atividade turística educativa com o patrimônio, por sua vez, demanda um trabalho interdisciplinar e abrangência de formas e conteúdos, que atinjam uma exploração racional, eficiente e, ao mesmo tempo, que valorize o potencial do patrimônio, sem que isso signifique dilapidação.

A formação continuada de educadores para este trabalho também é de fundamental importância, haja vista tratar-se de formar mediadores entre o conteúdo inerente ao patrimônio e os turistas, que no caso se colocam momentaneamente no papel de educandos do processo de educação patrimonial.

Por fim, este artigo é uma forma de construir uma ponte entre as áreas de educação, turismo e políticas patrimoniais, uma intersecção que ainda está em desenvolvimento, necessitando de açóes específicas e intencionadas de desenvolvimento da exploração educativa, sustentável e enriquecedora do patrimônio, o que seria uma iniciativa pública que beneficiaria as cidades turísticas e a valorizaçáo do patrimônio, bem como tornaria a atividade turística enriquecida de cultura pela mediação da educação patrimonial e os mecanismos de interpretação patrimonial.

\section{Notas}

1. Não é parte desta discussão, mas é importante deixar claro que a dimensão pedagógica, ou, mais amplamente, educativa, do trabalho com o patrimônio, não é a única possível na atividade turística de cunho cultural. Esta se pauta também no lazer, no entretenimento, na diversão, na contemplaçáo etc., nem todas com o compromisso de apropriação de conhecimentos. Esclarecido este ponto, e com a consciência dos limites da análise, o artigo somente se preocupará com a dimensão educativa da atividade turística com o patrimônio.

2. Esta afirmativa deve ser pontuada com uma análise realistas das relações internacionais, ainda mais em um momento histórico em que vemos deflagradas antigas disputas entre países poderosos como os EUA e a Rússia, no caso da Ucrânia. A paz e o respeito à diversidade são também função política e econômica, mas, de fato, é possível, pelo conhecimento e respeito à cultura alheia, promover açóes de ampliação cultural que levem à consciência de que as diferenças culturais náo ultrapassam o fato básico de que dividimos uma condição comum, que é a de sermos humanos.

3. Concepção de História veiculada pela chamada Escola dos Annales e publicada, especialmente, pela revista Annales: ecónomies, societés, civilisations, na França dos anos de 1930, e que tem como principais nomes Lucien Févre e Marc Bloch. A tendência histórica defendida nesta escola tem como pano de fundo a crítica ao Positivismo de Durkheim e Comte e sua concepçáo de História, reunida na chamada escola metódica. O seu objeto particular são os estudos de estruturas, não de grandes tempos históricos ou eventos. (BURKE, 1992) 
4. Para não aprofundar a discussão, que não é o foco do artigo, basta lembrarmos as datas comemorativas escolares, que exaltavam, por exemplo, figuras como Duque de Caxias e seus feitos heroicos na Guerra do Paraguai; ou os bandeirantes e sua bravura nas expediçóes no sertão brasileiro, enfrentando selvagens índios e as doenças, tudo em nome da construçáo do nosso país, alargando nossas fronteiras para o interior, descobrindo as riquezas etc.

5. Uma discussão que poderia ser realizada em outro trabalho, é a de que apesar de ter sido importante a mudança na consideração sobre o que é ou não patrimônio, não se pode deixar de lado o fato de que, numa perspectiva marxista da História, o fundamento da dinâmica histórica encontra-se, em última instância, nas relações de produção. (MARX, 1993; 1994) Desta forma, a consideração do cotidiano e outras vertentes da Nova História, se náo cotejadas com uma análise a partir da totalidade das relaçóes sociais, que leva inclusive a uma melhor compreensáo do cotidiano, pode reproduzir uma visão reducionista da realidade. (HELLER, 1977) Ao mesmo tempo, uma pesquisa que não tenha como base a realidade concreta pode deslizar em mecanismos de interpretação alheios aos movimentos reais da sociedade considerada, e, logo, náo serve como parâmetro para seu desvelamento. (SEVERINO, 2001; CARDOSO, 1977)

6. No Brasil, o reconhecimento do Patrimônio Imaterial é anterior à Convenção da Unesco. Por meio do Decreto no 3551, de 04 de agosto de 2000, o governo cria o Programa Nacional do Patrimônio Imaterial. (BRASIL, 2000) As primeiras manifestações a serem oficializadas pelo Fundo Nacional de Cultura foram a Expressão Gráfica e Oralidade entre os Wajãpi, indígenas do Amapá e o Ofício das Paneleiras de Goiabeiras, do Espírito Santo.

\section{Referências}

ANDERSON, P. Balanço do neoliberalismo. In: SADER, E.; GENTILI, P.(Orgs.). Pós-neoliberalismo: as políticas sociais e o estado democrático. 6. ed. Rio de Janeiro: Paz e Terra. 2003.

BANDUCCI JR, A.; BARRETTO, M. (Orgs.). Turismo e identidade local: uma visão antropológica. Campinas: Papirus, 2001.

BARRETTO, M. Turismo e legado cultural: as possibilidades do planejamento. 4. ed. Campinas: Papirus, 2003.

BRASIL. Decreto n. 3551, de 04 de agosto de 2000. Institui o Registro de Bens Culturais de Natureza Imaterial que constituem patrimônio cultural brasileiro, cria o Programa Nacional do Patrimônio Imaterial e dá outras providências. Brasília, DF., Diário Oficial da Uniáo, 05 de agosto de 2000. Disponível em: <http://www.planalto.gov.br/ccivil_03/ decreto/D3551.htm $>$. Acesso em 01 de maio de 2014.

BURKE, P. (Org.). A Escrita da História - Novas Perspectivas. São Paulo: Editora Unesp, 1992.

CARDOSO, M. L. La construcción de conocimientos: cuestiones de teoría y método. México D.F.: Ediciones Era, 1977.

CHOAY, F. A alegoria do patrimônio. São Paulo: Unesp; Estação Liberdade, 2001.

COSTA, F. R. Turismo e patrimônio cultural: interpretaçóes e qualificação. Sáo Paulo: Editora Senac, 2009. 
DUARTE, N. A individualidade para-si: contribuição a uma teoria histórico-social da formação do indivíduo. Campinas: Autores Associados, 1993.

EVANGELISTA, J. Crise do marxismo e irracionalismo pós-moderno. São Paulo: Cortez, 2002.

FAORO, R. Os donos do poder: formação do patronato político brasileiro. 3. ed. Porto Alegre: Globo, 2001.

FERNANDES, F. A revolução burguesa no Brasil: ensaio de interpretação sociológica. Rio de Janeiro: Zahar, 1974.

HELLER, A. O quotidiano e a história. Rio de Janeiro: Paz e Terra, 1977.

GASTAL, S.; CASTROGIOVANNI, A. C. (Orgs.). Turismo na pós-modernidade. Porto Alegre: EDIPUCRS, 2003.

GRAMSCI, A. Cadernos do cárcere. Rio de Janeiro: Civilização Brasileira, 2001.

LARAIA, R. B. Cultura: um conceito antropológico. 14. ed. Rio de Janeiro: Zahar, 2001.

MARTINS, L. M. Da formação humana em Marx à crítica das pedagogias das competências. In: DUARTE, N. (Org.). Fetichismo da individualidade. Campinas: Autores Associados, 2004.

MARX, K.; ENGELS, F. A ideologia alemã. Rio de Janeiro: Martins Fontes, 1993.

. O capital: crítica da economia política. Livro 1. O processo de produção do capital. v. I. 14. ed. Rio de Janeiro: Bertrand Brasil, 1994.

MURTA, S. M.; ALBANO, C. Interpretar o patrimônio: um exercício do olhar. Belo Horizonte: UFMG: Território Brasislis, 2002.

MURTA, S. M.; GOODNEY, B. Interpretação do patrimônio para visitantes: um quadro conceitual. In: MURTA, S. M.; ALBANO, C. (Orgs.). Interpretar o patrimônio: um exercício do olhar. Belo Horizonte: UFMG; Território Brasilis, 2002.

OLIVEIRA, B. Aspectos lógico-epistemológicos da relação indivíduo-sociedade-genericidade no trabalho educativo. Educação, ano 10, n. 17, p. 11-32, dez. 2002.

PÉREZ, X. P. Turismo cultural: uma visão antropológica. España: Colección Pasos Edita, 2009.

SANTANA TALAVERA, A. ¿Nuevas Hordas, Viejas Culturas? La Antropología y el Turismo. Barcelona: Ariel, 1997.

. Mirando Culturas: la antropología del turismo. In: RUBIO GIL, A. (Ed.). Sociología del turismo. Barcelona: Ariel, 2003.

SANTOS FILHO, J. Ontologia do turismo: estudo de suas causas primeiras. Caxias do Sul: Educs, 2005.

SAVIANI, D. Pedagogia histórico-critica: primeiras aproximaçôes. 7. ed. Campinas: Autores Associados, 2000. 
SEVERINO, A. J. A pesquisa em educação: a abordagem crítico-dialética e suas implicações na formação do educador. Contrapontos. Revista de Educação da UNIVALI, ano 1, n.1, p. 11-22, jan.-jun., 2001.

SOARES, A.L.R. (Org.). Educação patrimonial: relatos e experiências. Santa Maria: Ed. UFSM, 2003.

UNESCO. Convenção para a salvaguarda do patrimônio cultural imaterial. Brasília: IPHAN, 2003. Disponível em: <http://unesdoc.unesco.org/images/0013/001325/132540por. pdf>. Acesso em 21 abr. 2008.

URRY, J. O olhar do turista. São Paulo: SENAC, 1996.

Recebido em 07 de julho de 2014.

Aprovado em 19 de janeiro de 2015.

DOI: http://dx.doi.org/10.1590/ES0101-73302015137387 